\title{
Teacher Collaboration Network in Higher Education: reflective visions from praxis
}

\author{
Teresa Romeu ${ }^{a}$, Montse Guitert ${ }^{\mathrm{a}}$, Albert Sangrà ${ }^{\mathrm{b}}$ \\ ${ }^{a}$ Computer Science, Multimedia and Telecommunication Studies, Open University of Catalonia (UOC), \\ Barcelona, Spain, $\quad{ }^{b}$ Educational Sciences, Open University of Catalonia (UOC), Barcelona, Spain.
}

\begin{abstract}
Online collaboration is a relevant teaching method and has become a priority in education and research. In addition, it is becoming an essential skill for teachers. Taking this fact into consideration, this study focuses on online collaboration from the teachers' perspective. The participants of our research develop their training activity in a fully online university and have teaching experience in online collaborative processes. Based on a case study methodology, the aim of this research is to develop an in-depth understanding of online collaborative hands-on experiences in context through their perceptions. The results provide evidence of the value of online teacher collaboration, which is useful not only for the improvement and innovation in their teaching, but also for their professional development and updating. It also highlights the value of online coordination to facilitate and promote the exchange of information and collaborative knowledge building for teacher-teacher collaboration.
\end{abstract}

Keywords: online teaching, professional development, Higher Education, teacher collaboration, teaching practice

\section{Introduction and current status}

Some initial issues seem relevant to be addressed in order to place the concept of teacher collaboration within an educational context. Teacher collaboration is not just simply contributing information or work and adding it on to reach a product but it also involves sharing views and objectives and building joint knowledge. Working in a collaborative way involves interdependence among the different members and a shared responsibility of the task in hand.

When teacher collaboration happens in an online context; its potentialities increase substantially since the environment offers innovative opportunities for interaction, communication and the production of knowledge (Harasim et al., 2000). In this line, Owyang (2008) affirms that the participants feel part of a group when the objectives are common. From this perspective, the analysis of the participants in an asynchronous network that work collaboratively offering help and support to the rest of the participants becomes a focus of interest in educational research.

The introduction of online technologies at Higher Education level has transformed the experiences of teachers. The teacher is both proactive to provide encouragement and reactive to respond to emerging issues. As was articulated by Anderson (2003), "teacher-teacher collaboration is critical to the current model of university based research production and evaluation" (2003, p. 5). Teachers could interact with one another in various virtual spaces, help each other with problems (Salmon, 2000), and work collaboratively on activities which improve teaching and learning practices and contribute to the collective knowledge of the group (Guitert et al., 2007).

According to Ernest \& Hopkins (2006), online collaboration among teachers is also essential for improving the courses and the teaching practice. Opportunities for collaboration and communications between teachers need to be integrated into the teaching practice.

The potential of online teacher collaboration for developing their teaching activity through the online method makes it possible to increase the management of knowledge (Area, 2006), permits the 
sharing and exchange of materials and resources, and the producing of documents in a collaborative way as well as their dissemination. Different studies highlight this interest of its use in the educational system as a source of resources and as a platform to work with these resources. It is for this reason that web 2.0 increases participation thus permitting the production and the publication of its own contents.

It is at this point that analysing teacher-teacher collaboration is justified, and at the same time corroborating through various studies that value the importance of collaboration and teamwork, in particular, in multidisciplinary fields and virtual learning environments. Addressing collaboration from the perspective of the teacher that works collaboratively through the Net, entails a form of working that enables the sharing of resources to reach some objectives during a specific period of time, interacting and participating in a continuous and shared way (Garrison and Anderson, 2005), exchanging information and experiences which permit learning and to be enriched through working together (McConnell, 2006; Suárez, 2010). In collaborative learning communities (Wenger, 2002), professionals discuss, construct and share ideas, generate and enact new strategies for their work environment and, above all, share insights about what they have learned. Such collaborative enquiry may result in a dynamic co-construction of knowledge (Tillema \& van der Westhuizen, 2006).

Despite the existence of collaborative experiences among teachers in non-university education (Vance, 2001), and from numerous studies regarding professional teacher development (Area, 2006), as well as the experiences regarding collaboration in Higher Education from the students' point of view (Guitert et al., 2007), few studies have been observed that focus on researching online collaboration among teachers (Ernest et al., 2013).

Finally, many authors offer metaphors to encompass the role of online coordination. The literature review in this particular field has been associated to an online moderator (Gairín-Sallán et al., 2010) or an online instructor (Gray, 2004). Salmon (2000) renames instructors as "e-moderators". Furthermore, Wenger (2002) describes one of the key success factors for communities of practice is the existence of coordination, or a function of coordination, whose main mission is to encourage participation and manage contents to be exchanged.

From the visions of the communities of practice, the members come in a variety of forms and levels of participation but often with a core group where an "active member takes on a leadership role in the centre of the community" (Wenger et al., 2002, p. 58). The concept of coordination is located within this approach. Starting from this principle, the coordinator in an online teacher group is understood to promote interaction through its regular presence in the different online spaces, and encourages teachers to take an active teaching role thus improving quality and promoting online teacher collaboration (Ernest \& Hopkins, 2006).

\section{Methodological issues}

Collaboration among teachers is regarded in many models of teacher professional development as an important means for enhancing teacher professional growth (Hargreaves, 2003), and this is based on the framework of some previous research in which a systemised study was carried out on the processes of online collaboration among teachers (Romeu, 2011). This research focuses on examining the perceptions teachers have about what online collaboration provides them through a specific case study analysis (Simons, 2009). The case study (Stake, 2005) focuses on a team of teachers that teaches a transversal core course (ICT Competencies) online, which is part of all UOC degrees.

To respond to this objective, the following research questions are raised:

- How do teachers perceive the role of online coordination?

- Which are the reasons why this team of teachers collaborate online?

- What are the benefits of online collaboration for teachers? 


\section{Research setting}

This research addresses the experience of online collaboration among teachers in Higher Education, specifically in a fully online university which makes intensive use of ICT. The team of teachers are involved in teaching ICT competencies and work in a specific context, that of a virtual university environment.

The selection about this case study is justified because these teachers regularly work together, given that they (a) are linked through the sharing of ICT contents that are in permanent development, (b) communicate and interact entirely in a specific virtual space, (c) also have an online coordination, (d) have an interdisciplinary profile because they give academic feedback in different degrees and, (e) make students' competency acquisition easier, one of which is collaborative work. Their singularity and characteristic features are presented in table 1 :

\begin{tabular}{|c|l|}
\hline$\%$ & \multicolumn{1}{|c|}{ Characteristic features } \\
\hline $98.7 \%$ & Get connected at least once a day \\
\hline $80.2 \%$ & Have already been students at the UOC \\
\hline $64.7 \%$ & Have had online collaboration teaching experiences at the UOC \\
\hline $48.5 \%$ & Have had online collaboration teaching experiences outside UOC \\
\hline $36.1 \%$ & Participate at least once a day in the common virtual space as teachers \\
\hline
\end{tabular}

Table 1: The singular character of the team of teachers' case study.

\section{Design of the research}

Online collaboration takes on a central function since the Internet makes online teacher collaboration easier to participate with a shared interest. In this research, online teacher collaboration takes place in the virtual space of the UOC virtual campus and, specifically, in the virtual staffroom (Anderson \& Kanuka, 2003).

A qualitative and interpretative research methodology has been adopted with the objective of obtaining a more global knowledge of the reality, and a mixed method approach has been used. The technique for the gathering of data, during two semesters, was through virtual observations, the analysis and review of digital documents and an online questionnaire.

To understand the interaction among teachers (Silverman, 2013), virtual observations were carried out (Kozinets, 2010) in two virtual spaces in the staffroom (Noticeboard and Forum), taking as a reference the dimensions of the model by Garrison and Anderson (2005). The dimension "teaching presence" in the 'Noticeboard' space of the staffroom, as the space of communication of Coordination, posting a total of 126 messages, and the dimensions "cognitive presence" and "social presence" in the "Forum' space of the staffroom, as the common communication space for teachers, posting a total of 735 messages.

An anonymous online questionnaire, with open-ended questions, was designed in order to investigate the teachers' perception based on research questions. They were validated by expert judges and were administered voluntarily in the final phase of the study. The online questionnaire was sent to 85 teachers, and was completed by 71 (i.e., a response rate of $83.5 \%$ ). 
All this data, of both a quantitative and qualitative nature, was triangulated (Taylor and Bogdan, 2002), based on the dimensions presented, and contrasting techniques, agents and methods with the aim of getting a thorough understanding of the analysis of the collaboration experience.

\section{Results and discussion}

The interrelationship between teachers is one of the forms of interaction of online education that permits the intensive use of communication and information technologies, and which enables one to derive the full benefit of information in a virtual environment (Garrison and Anderson, 2005).

To understand online collaboration among teachers in this case study; first of all, it is important to identify the virtual staffroom as a shared space in the UOC virtual campus in which all the team has access to, and it is where teaching experiences are exchanged. In this line, some teachers have affirmed so: "Our virtual space is an asynchronous community of teachers, a contrasted place of reference where information is found to resolve doubts and to get advice that can be applied" (TEA$01)$.

\section{The role of online Coordination}

According to Garrison and Anderson (2005), "teaching presence" is a dimension which includes designing, facilitating and promoting educational experience. In a university context, other teaching figures can exist which contribute to teaching presence. In the context of the UOC, this function can be carried out by a Coordinator of teachers, who designs and organizes the subject, sends messages to online staffroom-teachers to facilitate discourse, and provides them with direct instruction. Those functions have been developed in the 'Noticeboard' space.

The role of online Coordination takes on a core factor within the dynamics of online collaboration among teachers. Some experts propose the figure of the online moderator (Gairín-Sallán et al., 2010) or an online coordinator (Ernest \& Hopkins, 2006), which facilitates and promotes the permanence of members in the group.

To respond to the first research question, the opinions of the teachers were collected and the messages were categorised in the 'Noticeboard' space of the staffroom. Furthermore, a previous study was carried out on the role of Coordination in virtual educational contexts (Guitert et al., 2007).

The research provides some relevant data, in that $90.4 \%$ of the teachers consider that Coordination enables interaction among teachers by means of the virtual staffroom. One of them comments: "coordination facilitates interchange among teachers, guides teaching practice, makes proposals to dynamise the group and achieves shared-teaching, and boosts the interchange of resources and tools" (TEA-02). In addition, $85.7 \%$ of the teachers perceive positively the role of Coordination as a facilitator of teaching strategies; "coordination proposes, suggests, guides and facilitates that the information among the team of teachers flows and is shared" (TEA-03).

Additionally, $91 \%$ of the teachers consider that Coordination makes the virtual staffroom space more dynamic, and thus fostering the interchange of information. In this line, one of the teachers "coordinates, regulates, stimulates, guides, leads and incites that we participate and collaborate" (TEA-04). Another teacher suggested: "Coordination impulses us to be more involved so that the teaching activity in the virtual classroom is common and agreed by all of us" (TEA-05).

It is a way to foster continuous interaction among the team of teachers in order to promote the generation of ideas. In this regard, one of the teachers states: "I consider that the role of coordination has a positive effect on our opinions and comments" (TEA-06).

As a summary, it can be stated that the teachers participating in the study confirm the importance of the role of Coordination and validate the functions linked to design, organisation, dynamisation of the group, follow-up and the professional development of the teacher. 


\section{Reasons why a team of online teachers collaborate}

To examine why teachers collaborate, their interactions related to "cognitive presence" and "social presence" were analysed, adapting the model to three dimensions (see Table 2). The percentages shown have been calculated out of the total number of messages under analysis.

\begin{tabular}{|c|c|l|l|}
\hline $\begin{array}{c}\% \\
\text { messages }\end{array}$ & $\begin{array}{c}\text { Dimensions from } \\
\text { Garrison's model }\end{array}$ & \multicolumn{1}{|c|}{$\begin{array}{c}\text { Adaptative } \\
\text { Dimensions }\end{array}$} & \multicolumn{1}{|c|}{ Reasons to collaborate } \\
\hline $79 \%$ & \multirow{2}{*}{$\begin{array}{c}\text { Cognitive } \\
\text { presence }\end{array}$} & Teaching practice & $\begin{array}{l}\text { Share teaching experiences and contrast points of } \\
\text { view about teaching activity }\end{array}$ \\
\cline { 1 - 3 } & $\begin{array}{l}\text { Professional } \\
\text { development }\end{array}$ & $\begin{array}{l}\text { Share beyond the teaching activity: increases } \\
\text { teachers' self-confidence }\end{array}$ \\
\hline $18 \%$ & Social presence & $\begin{array}{l}\text { Social } \\
\text { collaboration }\end{array}$ & $\begin{array}{l}\text { Share student experiences create affective links } \\
\text { among them }\end{array}$ \\
\hline
\end{tabular}

Table 2: Reasons to collaborate (adaptive dimensions from Garrison's model, 2005).

"Cognitive presence" is defined as "the extent to which the participants in any particular configuration of a community of inquiry are able to construct meaning through sustained communication." (Garrison et al., 2000, p. 89). Taking into account that the community is formed by teachers and that the interaction among them is very valuable for their roles as teachers, the cognitive element has been divided into two different dimensions: 1) teaching practice, and 2) professional development. Teaching practice has been understood as those cognitive elements related to the actual teaching of the course. This includes postings related to teaching strategies, sharing experiences and problems, dealing with student queries, procedural issues related to the subject, doubts from new teachers, technological issues, etc. Professional development has been understood as those cognitive elements that allow teachers to develop professionally which transcend day-to-day teaching. This category includes postings containing information on conferences, academic articles and materials which are not directly linked to the subject.

To respond to the second research question, the opinions of the teachers were collected and the messages were categorised in the staffroom space, as described in the Methodology section.

\section{Collaboration linked to teaching practice}

The reasons linked to teaching practice have a direct relationship with their activity as teachers in that it helps them to make their work easier and influences in a very direct way in an improvement in teaching and highlights the true sense of collaboration, and precisely those were the ones where more answers were obtained.

The vast majority of the messages are related to the teaching practice dimension (79\%). The teachers share teaching experiences and contrast points of view about teaching activity. In this respect, eight categories related to this dimension have been identified (Figure 1). The category of sharing students' doubts is the one that is most common and an example of such is: "Hello everybody, I have a student that has problems to access to the space of the shared disk. Have you found yourself in a similar situation?" (TEA-05). 


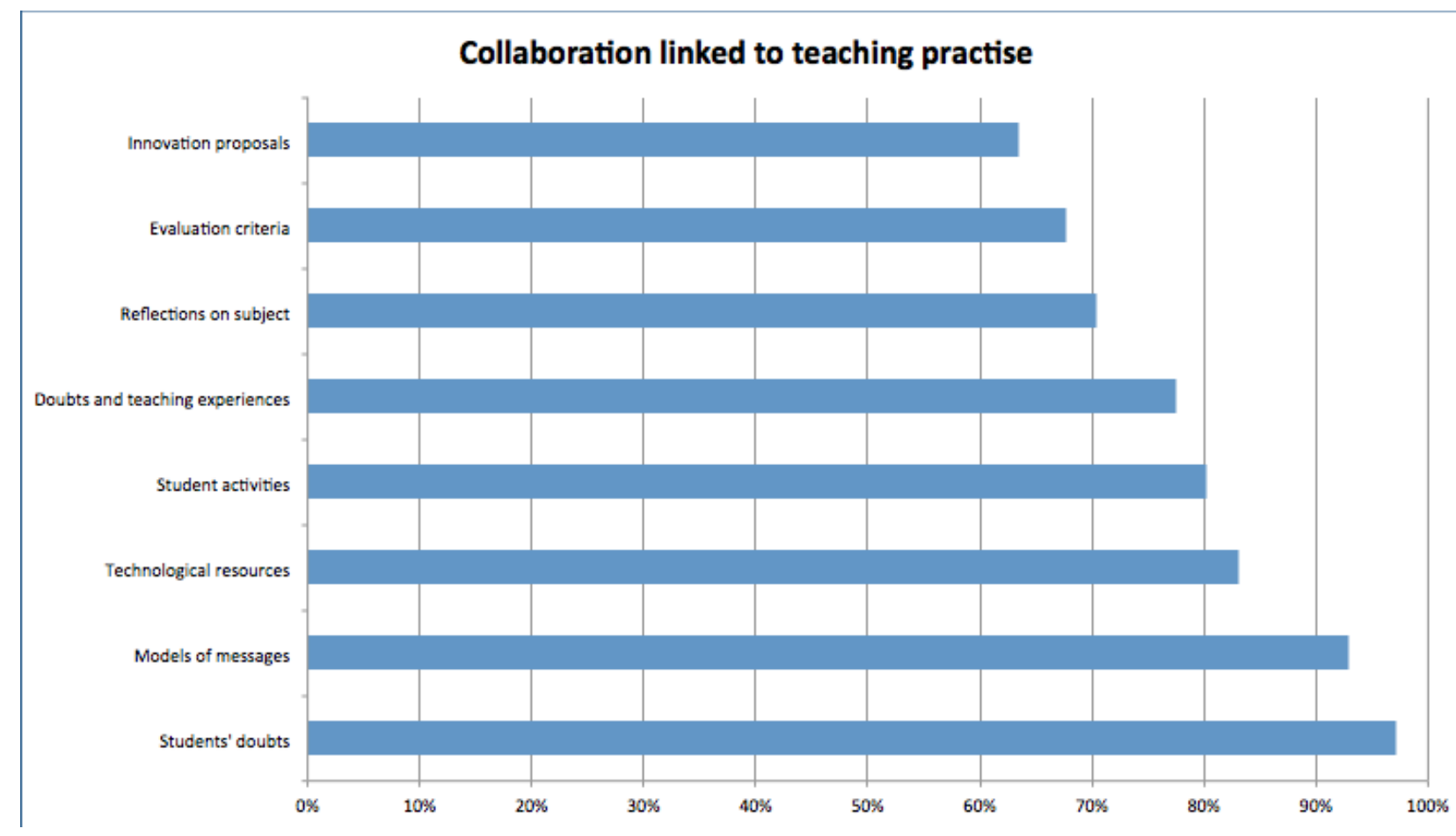

Figure 1: Collaboration linked to teaching practice: Categories.

The team of teachers consider that the knowledge and experiences that are shared in the virtual staffroom not only permit them to resolve the doubts that arise from the dynamics of teaching but also permit the improving of their work through contrasting other experiences. They consider that sharing teaching experiences proves this, in that they are based on praxis and teacher reflection. From the analysis of the perceptions of the teachers, these are some of the most relevant opinions:

"I especially value having models of messages available to me that can adapt almost directly to my virtual classroom with my students" (TEA-07).

"Knowing that despite being a virtual teacher, one has the back-up and support of all the team, and this means that whatever situation related to teaching can be regarded as something that concerns all of the team of consultants, and through all of us, we find the best way to deal with it" (TEA-08).

"Thanks to the experience of my colleagues, it helps me to be more proactive in the online classroom and be ahead of the situations that constantly arise" (TEA-09).

\section{Collaboration linked to professional development}

Beyond the reasons related to day-to-day teaching, there are reasons which emerge that increase the confidence of the teachers and that have been identified as interventions linked to professional development (Garrison, 2006). 21\% of the messages analysed make reference to this dimension. This online participation linked to professional development, and following Aparici \& Silva (2012), requires a high level of connection, commitment, collaboration, solidarity among the members of the community and is considered to be the second reason for collaboration and the object of analysis of this research. One of the teachers states: "In moments where I have not developed a genuine collaborative task, I have not been enriched professionally" (TEA-07). The category of sharing new resources (Figure 2) is the most common and one example shows this: "I send you a link to a monograph on the use of wikis in Higher Education..." (TEA-10).

According to Witney \& Smallbone (2011), the teachers frequently use wikis with students and among themselves. One of the relevant expressions is: "I understand the possibilities of the wiki 
environment better when it is used with my colleagues to update the activities and improve the feedback of the students" (TEA-04).

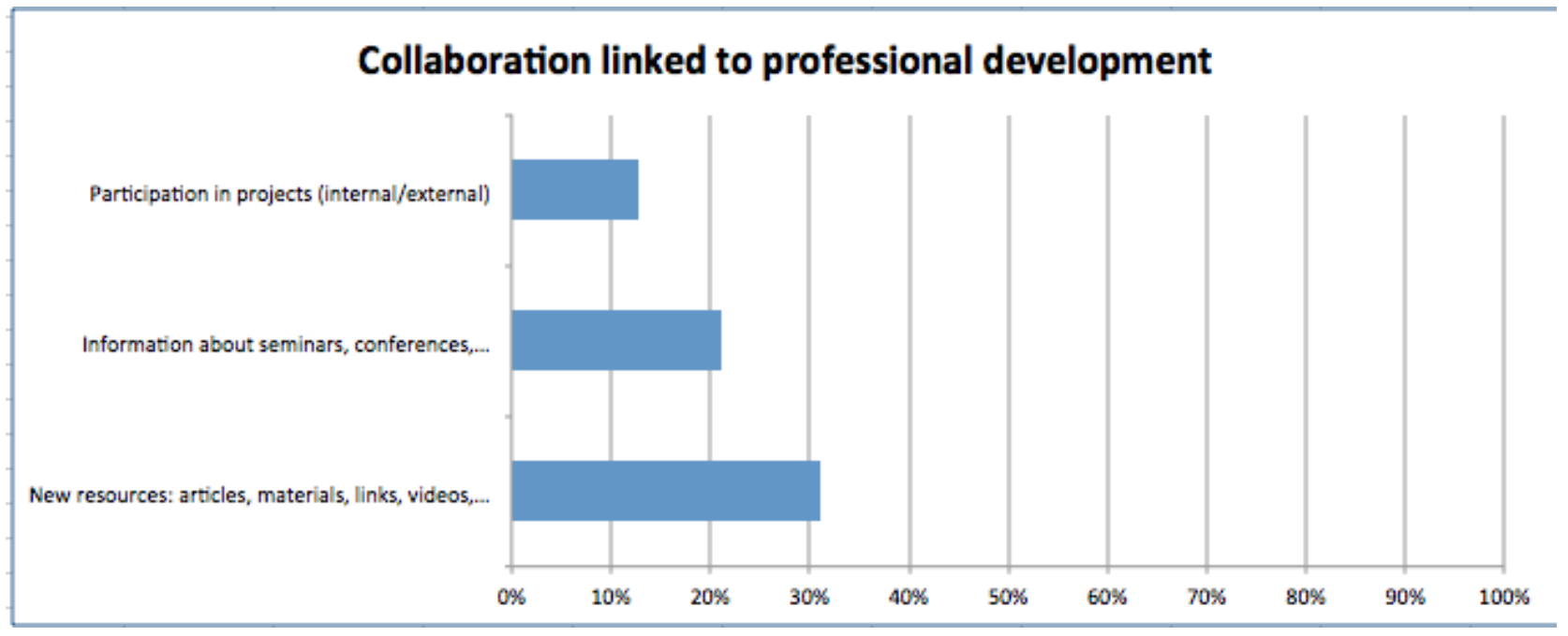

Figure 2: Collaboration linked to professional development: Categories.

The team of teachers consider that sharing information and knowledge that goes beyond the activity of teaching increases their confidence as teachers. From the analysis of the perceptions of the teachers, here are some of the most significant opinions:

"I am interested in participating in this Project that you have undertaken. I am involved in the topic of ICT in my company. If you send me more detailed information, I will begin to know where I stand" (TEA-11).

"The activity of the virtual staffroom makes one have a feeling of being trained and being constantly updated, thereby producing personal and professional enrichment" (TEA-12).

Social collaboration as an affective link

"Social presence" has been defined as "the ability of participants in the community of inquiry to project their personal characteristics within the community, thereby presenting themselves to the other participants as "real people" (Garrison et al., 2000, p. 10). In this context, the social factor is one of the aspects that helped to create a relaxed atmosphere in virtual environments (Suárez, 2010).

The analysis of this dimension highlights that the social factor that is impregnated in most interactions and is linked both to teaching practice and to professional development. $18 \%$ of the messages make reference to this dimension. However, the elements that have been identified in the UOC Staffroom and define this dimension are: humour, self-disclosure, greetings, welcome messages, expressions of gratitude, and expressions of encouragement. The social expressions were organized in these categories: 


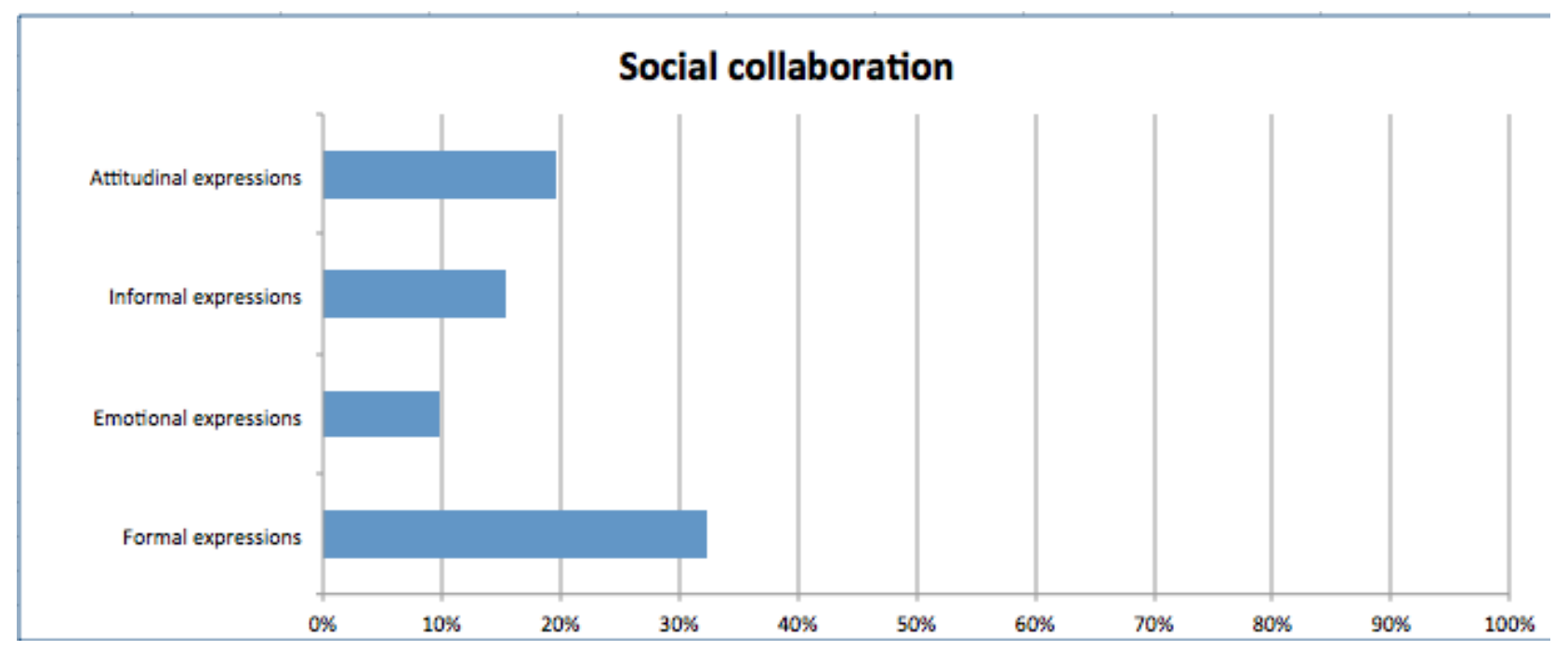

Figure 3: Collaboration linked to social aspects: Categories.

The identified category, related to social collaboration, with the higher percentage $(32.4 \%)$, corresponds to formal expressions which include personalised greetings, specific references to colleagues, farewells, ... expressions of affection which teachers normally use with their students in the virtual classroom.

One of the most important expressions that seeks group cohesion and group identity is the following: "When working virtually, one doesn't feel alone; through the direct involvement of my fellow colleagues, I feel accompanied" (TEA-13). The atmosphere is a persistent constant: "There was a climate of trust among us, and we could speak and discuss freely whatever topic" (TEA-14).

\section{The benefits from working collaboratively online}

The teacher team has experience in online collaborative processes and they actively participate in the virtual common space so their perceptions related to the benefits of online collaboration take on a special sense, contributing elements for the transfer to online collaboration in other contexts.

The items proposed to analyse the benefits of online collaboration come about from previous studies (Guitert et al., 2007), and are supported by Harasim et al., (2000), Area (2006), and Baran et al. (2011). The contrast with the team of teachers provides a vision of those that are directly involved and provides elements for the systemization of the aspects to be taken into account when developing online collaborative work processes.

The analysis of these items permits a response to the third research question. The scale to evaluate the benefits of the collaboration was from 4 to 1 (4: very beneficial, 3: beneficial; 2: not very beneficial; and 1: not beneficial at all). It is important to point out that option 1 was not used. Hence, just three response options are presented in Figure 4. 


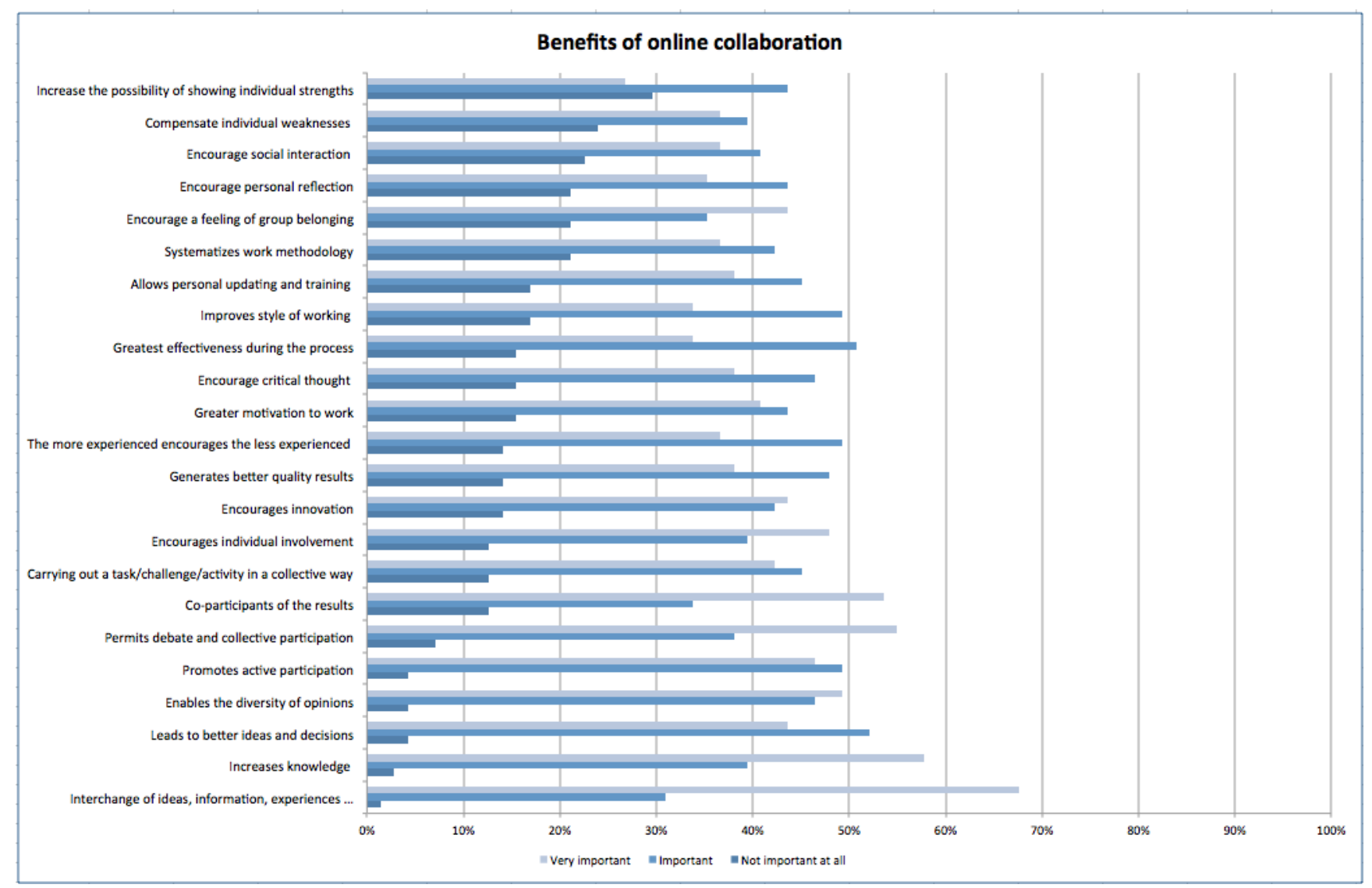

Figure 4: Benefits of online collaboration from the teachers' perspective.

The items most valued with a response greater than $50 \%$ are: interchange of ideas, knowledge building, permitting debate and active participation, and co-participant in the results.

Furthermore, in the open questions, they refer to the continuous support of colleagues when they have similar situations and have to develop strategies and tasks collaboratively:

"Being part of this team is for me a great source of knowledge, a means of constant updating and personal enrichment as part of a team" (TEA-02).

"Working collaboratively, contributing to the knowledge of each one should be the best training and updating for a teacher" (TEA-15).

"The group need is a priority; the individual need is a secondary concern" (TEA-16).

"The plurality of opinions regarding common teaching situations favours the development of innovative ideas regarding teaching" (TEA-17).

\section{Conclusions}

The results of the study show the possibilities provided by ICT in virtual environments in that it makes the sharing of the activity of the teacher easier, permitting not only contrasting praxis but also experience and knowledge and contributing methodological, pedagogical and technological improvements to teaching and professional development. Collaborating and improving teaching practice become inseparable and complementary elements in the educational panorama of the $21 \mathrm{st}$ century.

It is also important, to facilitate online collaboration, to have a common and permanent virtual workspace which permits ongoing reflection about teaching, promoting professional dialogue among 
the teachers and permanent interaction through reflection and debate (Area, 2006).

The conclusions arising from the study and which provide answers to the research questions are:

- Teachers perceived the importance of online Coordination and have validated the functions they perform to the point of systematising them. The role of online Coordination is to reinforce periodic and continued contact among the team of teachers, as well as managing and organising online teaching, fostering the interchange of information and promoting participation and thus shifting the responsibility of learning towards the same teachers. The five systematised functions are: (a) design, conceptualise, redesign thereby propitiating an improvement in online teaching and innovation; (b) organise and manage online teaching activity, and so favouring teaching strategies; (c) dynamise and promote virtual team interaction and collaboration; (d) carry out a follow-up and provide feedback of the online teaching activity; (e) facilitate the professional development of online teaching.

- Teachers perceived the reasons for online collaboration to be directly linked to their practice as virtual teachers. The categories identified from the dimensions analysed, are as affirmed: sharing and interchanging resources and teaching experiences to improve teaching practice, and generate new knowledge since one learns from the other. The teaching experiences that are shared are transferred to online teaching practice. Teacher's deep seated notions of what constitutes good teaching are critical to shaping teacher's practice. (Errington, 2004)

- Some relevant benefits of online collaboration from the visions of teachers is that it increases the capacity for collective reflection (e.g. interchange of ideas, information and experiences, permits debate and collective participation, and enables the diversity of opinions), have the support of colleagues (e.g. greatest effectiveness during the process, and co-participant of the results), and it is an opportunity to learn with others (e.g. the more experienced encourage the less experienced, to increase knowledge, and to improve style of working).

The results of the research also show that the teachers must dedicate more time daily to the management of online collaborative work. The benefits of collaborating has a direct impact on their teaching practice in the medium and long term, however, it is in the short term when it entails an additional effort, and in some cases, it is a cause of anxiety for them. Despite that, teachers perceived that the value of online collaboration is, on the one hand, the benefit of developing a professional competency, and on the other hand, the benefit of updating professional development and thereby improving their teaching practice.

\section{References}

Anderson, T. (2003). Modes of interaction in distance education: Recent developments and research questions. In M. Moore (Ed.) Handbook of Distance Education. (p. 129-144). Mahwah, NJ.: Erlbaum.

Anderson, T.; Kanuka, H. (2003). e-Research: methods, strategies and issues. Boston: Allyn \& Bacon. Aparici Marino, R., \& Silva, M. (2012). Pedagogía de la interactividad.Comunicar, 38, 20.

Area, M. (2006). Autoformación del profesorado. Colaboración a través de la red. Práctica docente, 3. Baran, E.; Correia, A.P.; Thompson, A. (2011): Transforming online teaching practice: critical analysis of the literature on the roles and competencies of online teachers, Distance Education, 32:3, 421-439

Ernest, P., Guitert Catasús, M., Hampel, R., Heiser, S., Hopkins, J., Murphy, L., \& Stickler, U. (2013). Online teacher development: collaborating in a virtual learning environment. Computer Assisted Language Learning, 26(4), 311-333.

Ernest, P., \& Hopkins, J. (2006). Coordination and teacher development in an online learning environment. CALICO Journal, 23(3), 551-568.

Errington, E. (2004). The impact of teacher beliefs on flexible learning innovation: some practices and possibilities for academic developers. Innovations in education and teaching international, 41(1), 39-47 Gairín-Sallán, J., Rodríguez-Gómez, D., \& Armengol-Asparó, C. (2010). Who exactly is the moderator? A consideration of online knowledge management network moderation in educational organisations. Computers \& Education, 55(1), 304-312. 
Garrison, D. R. (2006). Online collaboration principles. Journal of Asynchronous Learning Networks, 10(1), 25-34

Garrison, D. R.; Anderson, T. (2005). El e-learning en el siglo XXI: Investigación y práctica. Barcelona: Octaedro.

Garrison, D. R., Anderson, T., \& Archer, W. (2000). Critical inquiry in a text-based environment: Computer conferencing in higher education. The internet and higher education, 2(2), 87-105.

Gray, B. (2004). Informal Learning in an Online Community of Practice. Journal of Distance Education, 19(1), 20-35.

Guitert, M.; Romeu, T.; Pérez-Mateo, M. (2007). «Competencias TIC y trabajo en equipo en entornos virtuales» [artículo en línea]. Revista de Universidad y Sociedad del Conocimiento (RUSC). Vol. 4, n. ${ }^{\circ} 1$. UOC. [Fecha de consulta: 20/02/12]. http://www.uoc.edu/rusc/4/1/dt/esp/guitert romeu perez-mateo.pdf ISSN 1698-580X

Harasim, L.; Hiltz, S. R.; Turoff, M; Teles, L. (2000). Redes de aprendizaje. guía para la enseñanza y el aprendizaje en red. Barcelona: Gedisa.

Hargreaves, A. (2003). Enseñar en la sociedad del conocimiento: La educación en la era de la inventiva. Barcelona: Ediciones Octaedro.

Kozinets, R. V. (2010). Netnography: Doing ethnographic research online. Sage Publications.

McConnell, D. (2006). E-learning groups and communities. Poland: The Society for Research into Higher Education y Open University Press.

Owyang, J. (2008). Social network stats: Facebook, mySpace, Reunion. [Weblog entry, January 9.] Web Strategy by Jeremiah.

Romeu, T. (2011). La Docencia en colaboración en contextos virtuales: estudio de caso de un equipo de docentes del área de competencias digitales de la UOC (Doctoral dissertation, Universitat Oberta de Catalunya).

Salmon, G (2000) E-moderating: The key to teaching and learning online, Kogan Page, London.

Silverman, D. (2013). Doing qualitative research: A practical handbook. SAGE Publications Limited. Simons, H. (2009). Case study. Research and Practice. London: Sage Publications.

Stake, R. E. (2005), “Qualitative case studies” En N. K. Denzin and Y. S. Lincoln (eds.), The Sage handbook of qualitative research (3rd ed.), Thousand Oaks, CA: Sage Publications, pp. 433-466.

Suárez, C. (2010). Cooperación como condición social de aprendizaje. Editorial UOC, 2010. Pp. 124

Taylor, S. J.; Bogdan, R. (2002). Introducción a los métodos cualitativos de investigación. Barcelona: Paidós. Tillema, H., \& van der Westhuizen, G. J. (2006). Knowledge construction in collaborative enquiry among teachers. Teachers and Teaching: theory and practice, 12(1), 51-67.

Vance, L. A. (2001). Teachers' beliefs about co-teaching. Remedial \& Special Education, 22(4)

Wenger, E., McDermott, R. A., \& Snyder, W. (2002). Cultivating communities of practice. Boston, MA: Harvard Business Press

Witney, D., \& Smallbone, T. (2011). Wiki work: can using wikis enhance student collaboration for group assignment tasks? Innovations in Education and Teaching International, 48(1), 101-110. 